\title{
SHORT PERIOD MOTION EVENTS ON VARIEGATED GLACIER AS OBSERVED BY AUTOMATIC PHOTOGRAPHY AND SEISMIC METHODS
}

\author{
by \\ W.D. Harrison \\ (Geophysical Institute, University of Alaska, Fairbanks, Alaska 99775-0800, U.S.A.) \\ and \\ C.F. Raymond
}

(Geophysics Program, University of Washington, Seattle, WA 98195, U.S.A.)

and

P. MacKeith $†$

\begin{abstract}
A network of automated time-lapse cameras was deployed on Variegated Glacier, Alaska, to establish the temporal and spatial patterns of velocity change at a one-day time resolution. Results from the summers of 1979, 1980, and 1981 are presented; a surge occurred in 1982 and 1983. The principal velocity variations were pulses of increased speed, lasting about one day and referred to as "early"- or "late"-season motion events. The former recurred quasi-periodically on the upper part of the glacier in the early part of the melt season; the latter occurred later in the summer and were correlated with major storms or melting. Supplemental information about the occurrence of motion events was obtained from monitoring of seismic activity. Evidence for several other types of velocity changes was found.
\end{abstract}

\section{INTRODUCTION}

The recognition, in recent years, that water plays a key role in variability of glacier speed has brought new purpose into the old problem of field measurement of speed on different time scales. Here, we describe measurements of speed on Variegated Glacier, Alaska, based on automated systems distributed over the glacier length. These provide information on the spatial distribution of velocity variations, at a time resolution of about one day.

Variegated Glacier was singled out for detailed study in 1973 because of its surge behavior. The state of the glacier then was described by Bindschadler and others (1977) and its evolution, up to 1981 , by Raymond and Harrison (in preparation). The glacier surges every 15 to 20 years (Post, 1969), most recently in two episodes during 1982 and 1983 (Kamb and others, 1985). This paper is concerned with the years 1979, 1980, and 1981, just before the surge. In the summer of each year, there were brief intervals of increased speed lasting about one day, here referred to as motion events and distinguished according to "early" or "late" melt season occurrence. Some of the early season events were observed in great detail by Kamb and Engelhardt (in preparation) with conventional surveying techniques, and by Raymond and Malone (in press) with high-resolution strain measurements supplemented by seismic observations. The association of the early season events with propagation of hydraulic waves was made by Kamb and Engelhardt, with borehole pressure measurements, and by Humphrey and others (in press), with stream discharge measurements. Most

+ Deceased. of these measurements were restricted to the upper part of the glacier ( 3 to $9 \mathrm{~km}$ from the head) and to the early summer (June and July). The measurements described here establish a broader spatial and temporal coverage than the other measurements provided, but at lower resolution.

Speed measurements were made with a network of up to 10 automatic $35 \mathrm{~mm}$ cameras. These were spaced along the length of the glacier on the margin and sequentially photographed targets on the glacier surface. Supplementary data about the occurrence of motion events were gathered by up to six counting seismometers which recorded highfrequency ice quakes.

\section{DESCRIPTION OF SYSTEMS}

Several automatic camera systems for measurement of glacier motion have been described (Flotron, 1973; Krimmel and Rasmussen, this volume). The distinguishing features of our system are low cost and small size and weight. These were important in our applications because of the need to deploy many cameras to obtain good spatial coverage, and to do so in tenuous locations without helicopter support.

Our system uses $35 \mathrm{~mm}$ Olympus components: camera bodies, winders, 250 exposure film magazines, and 50, 100 or $300 \mathrm{~mm}$ lenses. These are inexpensive, but reliability is a problem. We have found it almost essential to have the date or time imprinted on each photograph and, to do so, we have adapted standard Olympus data backs to fit the 250 exposure magazines. The Olympus system will operate down to $-20^{\circ} \mathrm{C}$. Each camera is operated by a specially-designed two-channel device which controls camera power and shutter and is triggered by the alarm of a quartz-regulated wristwatch. Power sufficient for a year of operation is supplied by alkaline batteries. The system was initially mounted in a single, ventilated enclosure, made from wood. After 1981, the enclosure has been a gasketed, almost airtight, desiccated, $0.36 \times 0.31 \times 0.17 \mathrm{~m}$, aluminum box. Total mass, with a $300 \mathrm{~mm}$ lens, is $8 \mathrm{~kg}$. On Variegated Glacier, the enclosures were mounted on posts of 2 inch $(0.05 \mathrm{~m})$ water pipe via a two-dimensionally-adjustable clamp. We now use dome head aluminum tripods, built into a cairn, if possible, to which the enclosures mount via the base of a surveyor's level, fastened to their bottoms. We usually use black and white, thin-base film, which permits 400 exposures to be accommodated by the 250 exposure magazines.

Targets on the glacier, consisting of black balls subtending an angle of 35 seconds, were found satisfactory for $300 \mathrm{~mm}$ lenses. Daily ablation, as well as speed, can be measured; for this we use two adjacent targets, one fixed 
on a stake drilled into the ice and the other resting on the ice. The coordinates of the image of the target in the film plane were obtained in 1979 with a measuring microscope, in 1980 and 1981 with an automated version of the same thing, of which the normal function is the scanning of bubble-chamber photographs, and, subsequently, with a digitizing table with $0.025 \mathrm{~mm}$ resolution, onto which the negatives were projected with a magnification of roughly 30. Because the photography was uncontrolled by fixed markers on the rock, image film-plane coordinates were determined by reference to the edges of the photograph.

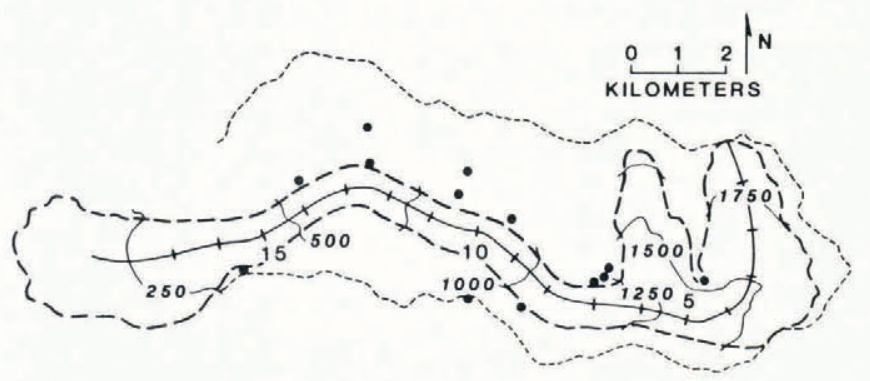

Fig.1. Map of Variegated Glacier. The scale along the center line gives distance from the head in $\mathrm{km}$. Dots show camera stations used between 1979 and 1985 .

Photogrammetric theory was used, first to determine the orientation of the camera from surveyed points in the field of view and, secondly, to determine the absolute position of the target from the film-plane coordinates of each sequential target image. For the first task, two surveyed positions of the target itself were used, when possible. When only one was available, the rotation of the camera about its axis had to be assumed to be zero; this was usually checked in the field with a level. The second task required determination of the horizontal projection of the trajectory of the target, which was determined by the same two surveys, and the assumption that the projection was linear. When only one survey was available, the direction was interpolated from other sequential survey data along the glacier.

The angular resolution of the system, including the digitization process, approaches 5 seconds of arc with a $300 \mathrm{~mm}$ lens. The angular position of a target can be measured to this accuracy only if there are good control points in the field of view, which we lacked on Variegated Glacier. When one depends on camera mounting stability for angular references, the accuracy is erratic and suffers from systematic effects, but 15 or 20 seconds seems fairly typical, judging from repeated determination of camera orientation, or repeated measurements of fixed points. This corresponds to a velocity error of typically $0.05 \mathrm{~m} / \mathrm{d}$ for a measurement interval of $1 \mathrm{~d}$. Vertical stability is poorer.

Seismic activity of the glacier was monitored initially with one standard micro-earthquake drum recording unit. The recordings showed the occurrence of ice quakes, characterized by high-frequency $\left(\sim 10^{2} \mathrm{~Hz}\right)$, short-duration $(1-2 \mathrm{~s})$ seismic signals. The rate of occurrence varied dramatically in a way correlated with ice straining (Raymond and Malone, submitted). During motion events, the occurrence rate was so high that it was impossible to count seismic events because of the saturation of the drum. The seismic signal character and the timing of high seismic activity in comparison to the temporal and spatial pattern of ice straining showed the high-frequency ice-quake sources were predominately local, within $1 \mathrm{~km}$ of the recording unit.

Counting seismometers, operated in 1980 and 1981, provided a simpler monitoring method. They have been described by Raymond and Malone (in press). The principal components were a geophone, specially-designed detection electronics to convert a seismic signal into a single pulse, and a pulse counter. The system counted the number of high-frequency seismic events in a set time interval (usually one-half or one hour) and recorded the counts sequentially. In the first summer, some difficulty with detection electronics caused periods of data loss. Another

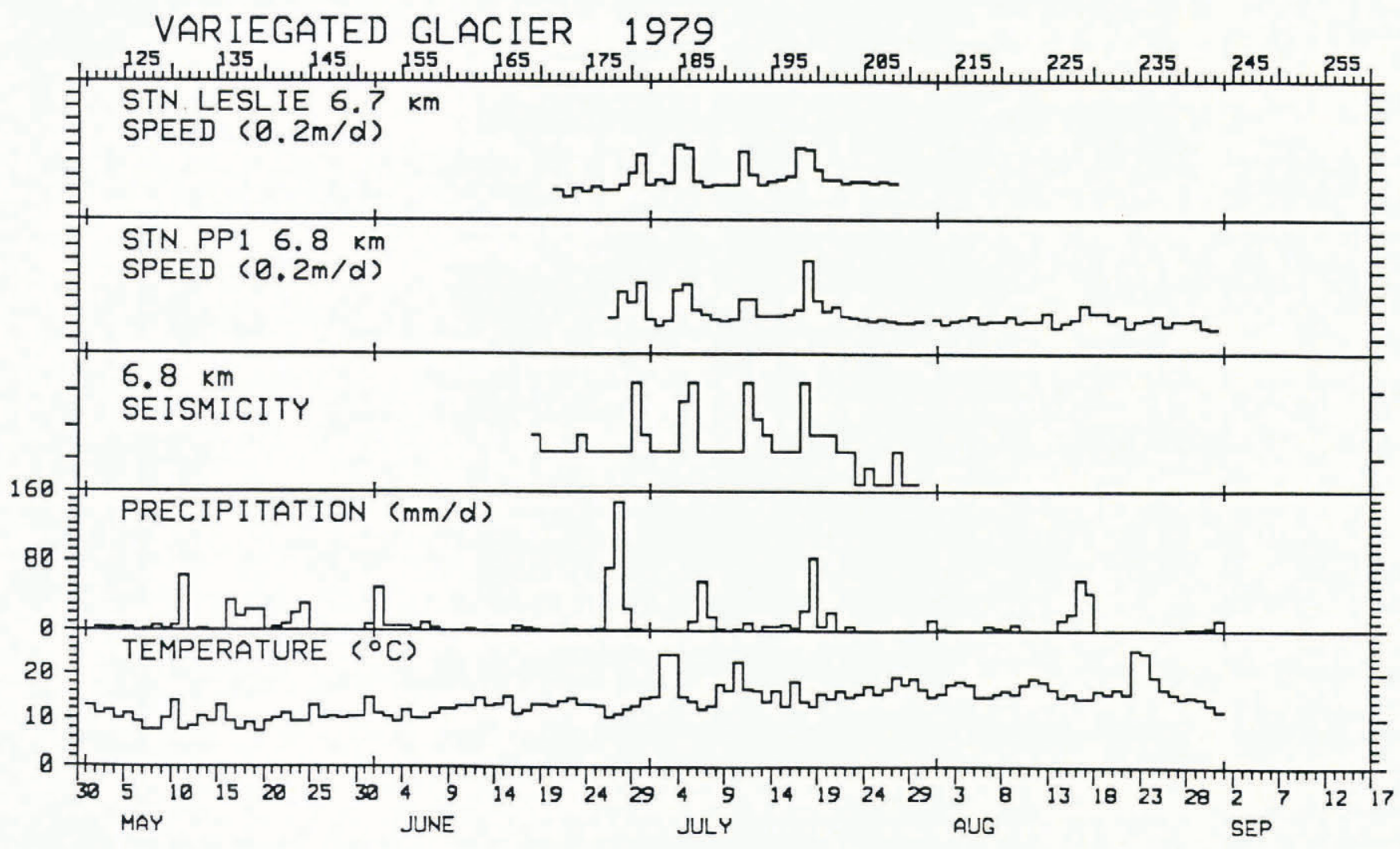

Fig.2. Horizontal speed, seismicity, and Yakutat weather data from 1979. In top panel, speed was determined from photography using images at 9:00 each day. Second panel shows speed from conventional surveying. Seismicity is a semi-quantitative estimate of activity, based on drum record. The zeros of all scales are indicated by the horizontal line. 


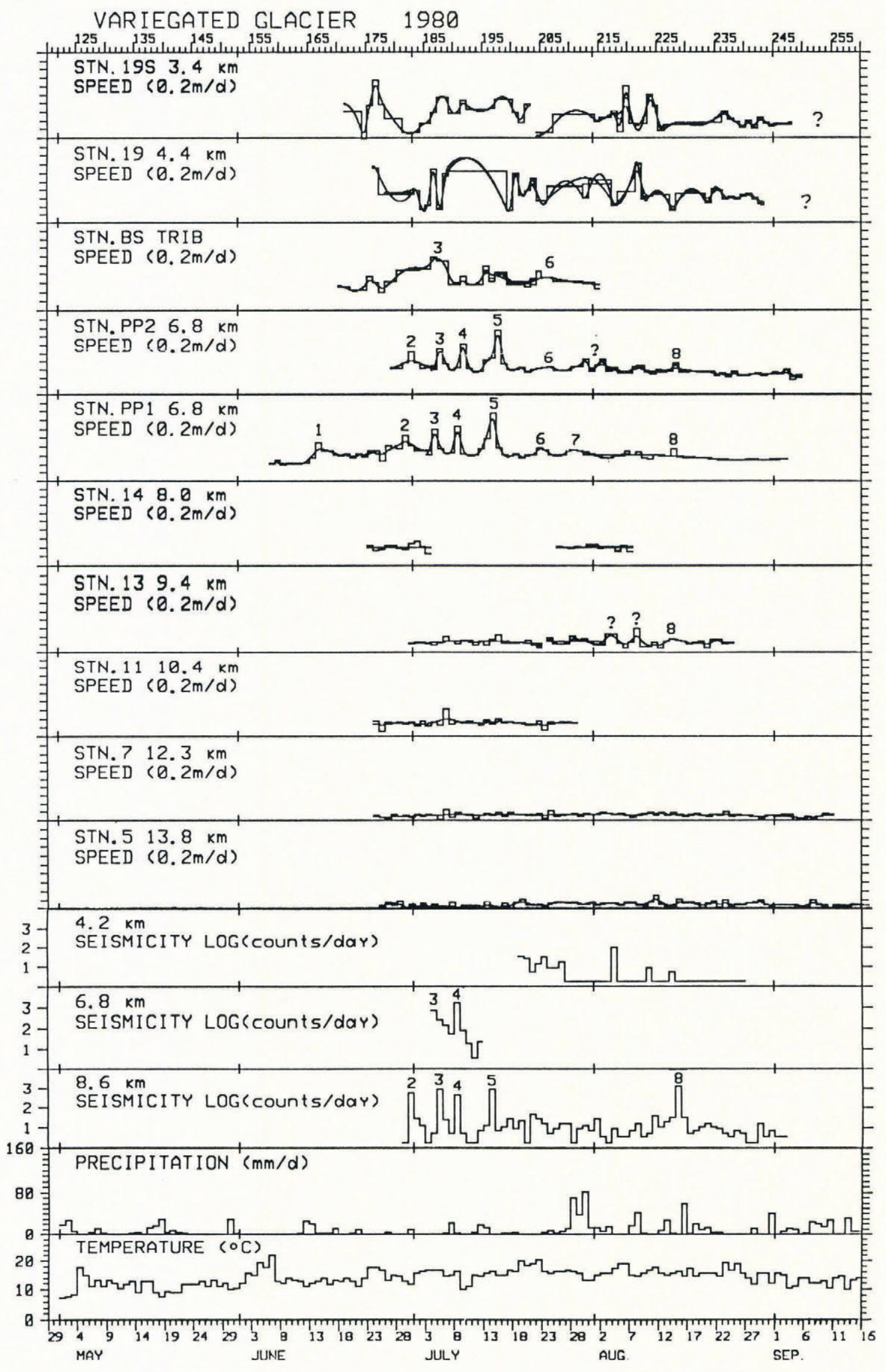

Fig.3. Horizontal speed from camera data, seismicity, and Yakutat weather data for 1980. Camera at station PP1 took one photograph daily at 9:00. All other cameras took photographs at 6:00 and 18:00. Only morning data are shown. Doubled traces show measurements from two independent targets. Note $\log$ scale for seismic activity. Peaks labelled "?" may be due to camera instability or other noise sources. Smooth curves are cubic splines, constrained to fit the data within the errors. 


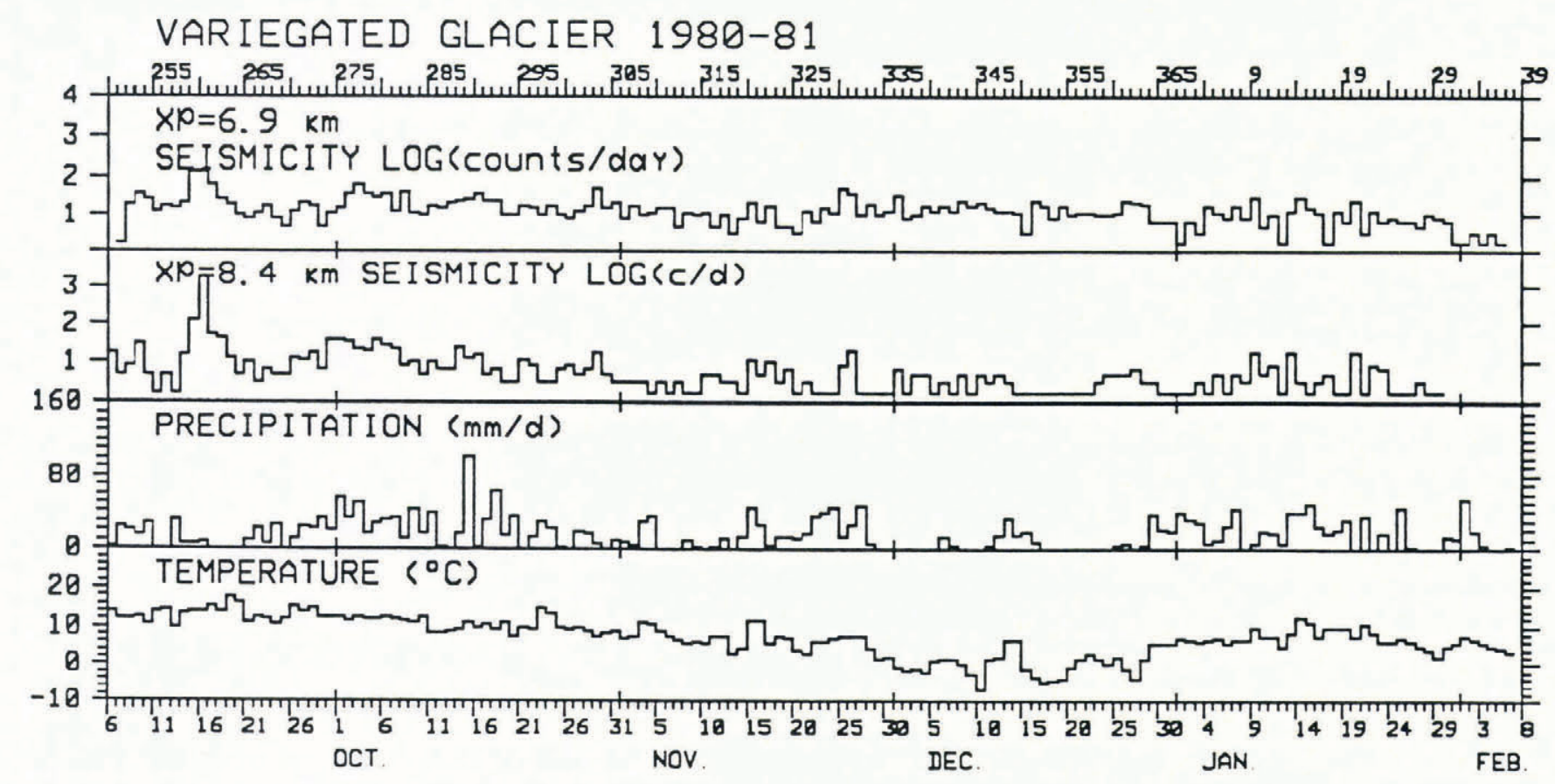

Fig.4. Seismicity and Yakutat weather data for fall and early winter 1980-1981.

problem causing data loss was the melting out of the geophone during summer ablation. The system could be operated for six months on a 30 ampere-hour battery.

The sensitivity of the system depended on geophone location and installation. At geophones embedded in old snow or firn on the glacier, recorded seismic events were typically less than $5 \mathrm{~h}^{-1}$ and usually 0 or $1 \mathrm{~h}^{-1}$ during intervals between motion events. During motion events, the count rate could climb to more than $10^{2} \mathrm{~h}^{-1}$ for a severalhour period. At geophones embedded in soil on the margin, background seismic activity was higher than on the glacier, but heightened seismic activity caused by ice quakes during motion events was still detectable.

Further information about the photographic and seismic techniques is given in section IV.
III. TEMPORAL AND SPATIAL PATTERN OF VARIEGATED GLACIER MOTION EVENTS

Figure 1 is a map of Variegated Glacier showing camera locations. On it is a center-line scale, graduated in kilometers from the head of the glacier, which serves to define the positions of cameras, targets, and seismometers. A camera at station BS TRIB observed the lower part of the tributary basin.

\section{A. Measurements in 1979}

One camera and one drum seismometer were operated in 1979 at $\mathrm{Kms} 6.7$ to 6.8 . Results for velocity and seismicity are shown in Figure 2. Weather data are also shown; they are from Yakutat, $55 \mathrm{~km}$ to the SSW, and are not completely representative of glacier conditions. Four

\section{TABLE I. "CATALOGUE OF MOTION EVENTS SENSED BY PHOTOGRAPHY AND SEISMOMETERS IN 1980."}

Notation for motion event occurrence:

definite $=\mathrm{y}$, probable $=\mathrm{p}$, uncertain $=\mathrm{u}$, absent $=\mathrm{n}$, no data $=-$

Footnotes indicate availability of information from other sources about a motion event at a given location or vicinity, or in the discharge stream.

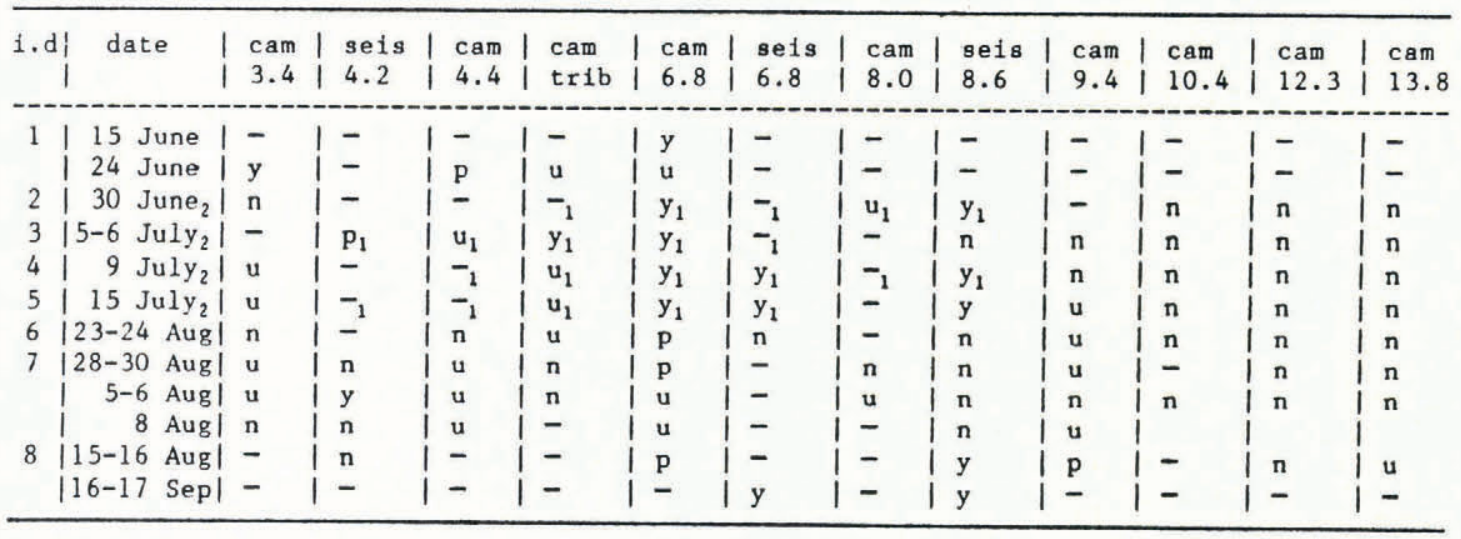

1 Kamb and Engelhardt (1985) or Raymond and Malone (1985)

2 Humphrey and others (1985) 
early-season motion events are apparent in both the camera and seismometer data on 29 June, 5 July, 11 July, and 17 July. A weak event occurred on 18 August.

B. Measurements in 1980

Data were obtained from nine cameras and three counting seismometers in summer 1980. Results are shown in Figure 3. Interpretation of the data at $\mathrm{Kms} 3.4$ and 4.4 is prevented by unexplained noise and gaps caused by bad weather. Five early-season motion events were observed

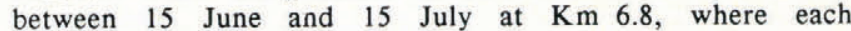
successive motion event was stronger. Subsequently, there were at least three other events of lower amplitude occurring from mid-July to mid-August, with evidence coming from both camera and seismometer data. Two counting seismometers were operated in early winter, 1980-1981. The seismic activity is shown in Figure 3. An apparently strong seismic event occurred in mid-September, but the rest of the winter up to end of January 1981 showed no strong anomalous activity.

Table I catalogues the motion events for 1980 and it includes the results of the more detailed measurements described previously. Events detected by cameras, with some certainty in the record, are numbered. Events detected by seismometers alone, or with only uncertain indication in the camera record, are not numbered. On 17 July 1980, surveyors walking on the glacier at $\mathrm{Km} 12.4$ noticed an interval of audible cracking, lasting about one-quarter hour. On the same day there was a sharply-peaked rise in turbidity recorded at the stream (Humphrey and others, submitted). This event was not detected by any instrumentation on glacier, including the camera at

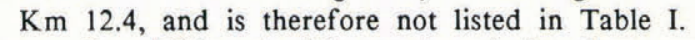

In addition to this event and the sharp motion events, there were more subtle modes of velocity change, which seem to be somewhat greater than the observational errors. At $\mathrm{Kms} 12.3$ and 13.8, there were long-term speed increases, starting in the second and third weeks of July. Subsequently, there was a more gradual reduction in speed in about the third week of August. These features are most evident as a change of slope in a plot of target coordinate versus time (Figure 5). Also on this plot can be seen a temporary break in slope at both positions on about 4
VARIEGATED GLACIER 1980

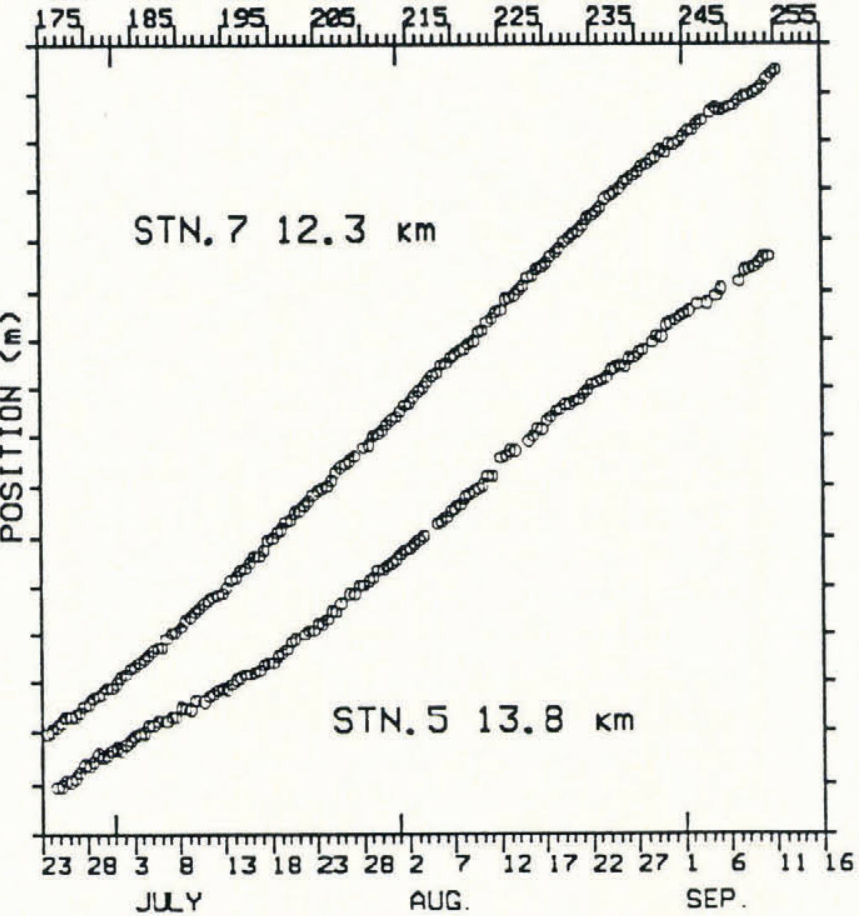

Fig.5. Longitudinal position versus time in 1980 for targets at $\mathrm{Kms} 12.3$ and 13.8 , plotted with arbitrary zeros.

September 1980, which represents a sudden deceleration followed by a rapid recovery (a "negative" motion event)

\section{Measurements in 1981}

Data were obtained from seven cameras and five counting seismometers in 1981. Results are shown in Figure 6 , and catalogued in Table II. Between 2 June and 15 July, a sequence of five early-season motion events, similar to the sequences of 1979 and 1980, occurred. The camera data

TABLE II. "CATALOGUE OF MOTION EVENTS SENSED BY PHOTOGRAPHY AND SEISMOMETERS IN 1981."

Notation for motion event occurrence:

definite $=y$, probable $=p$, uncertain $=u$, definitely absent $=\mathrm{n}$, no data $=-$

Footnotes indicate availability of information from other sources about motion events at a given location or vicinity, or in the discharge stream.

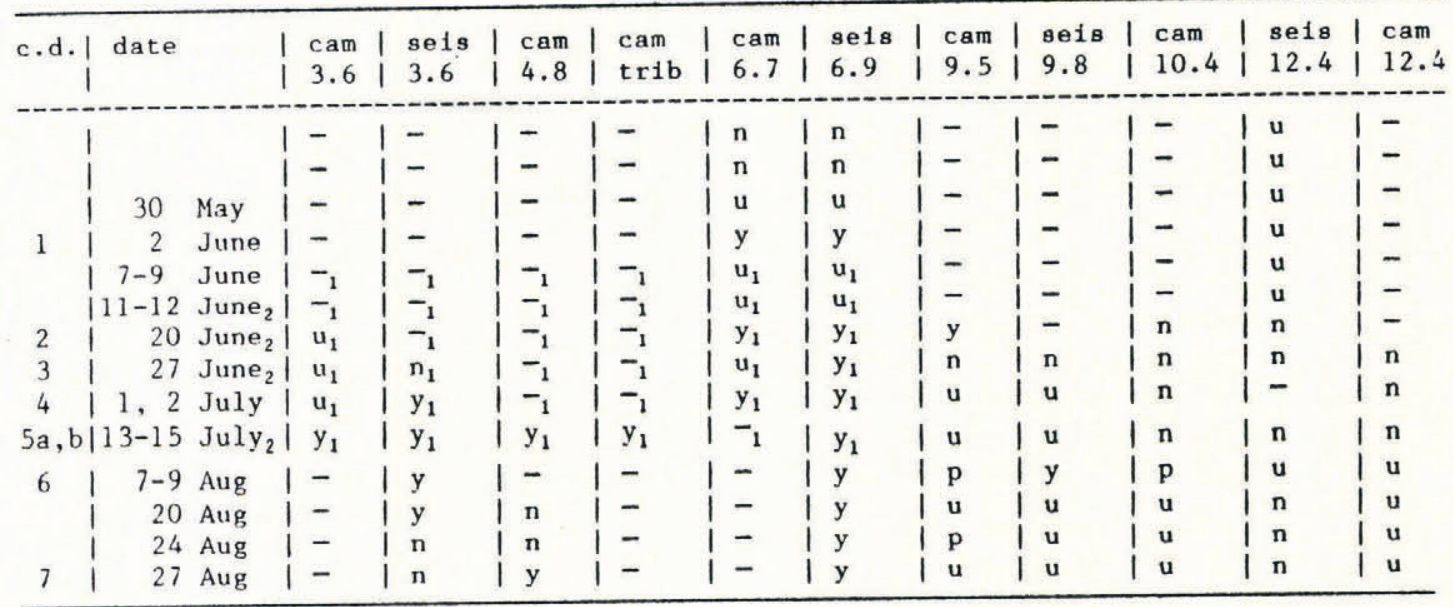

1 Raymond and Malone (1985) and Kamb (personal communication)

2 Humphrey and others (1985) 
VARIEGATED GLACIER 1981

س

STN. $1953.6 \mathrm{~km}$

SPEED $(0.2 \mathrm{~m} / \mathrm{d})$

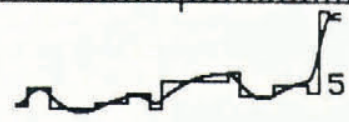

STN. $194.8 \mathrm{~km}$

SPEED $(0.2 \mathrm{~m} / \mathrm{d})$

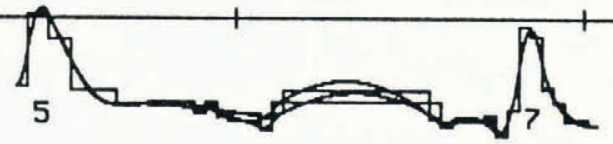

STN. BS TRIB

SPEED $(0.2 \mathrm{~m} / \mathrm{d})$

STN. MP 6.7 $\mathrm{km}^{1} 1$

SPEED $(0.2 \mathrm{~m} / \mathrm{d}$

andinnom

STN. $139.5 \mathrm{~km}$

SPEED $(0.2 \mathrm{~m} / \mathrm{d})$

STN. $1110.4 \mathrm{~km}$

SPEED $(0.2 \mathrm{~m} / \mathrm{d})$

STN. $712.4 \mathrm{~km}$

SPEED $(0.2 \mathrm{~m} / \mathrm{d})$

3. $6 \mathrm{~km}$ (on Glacier)

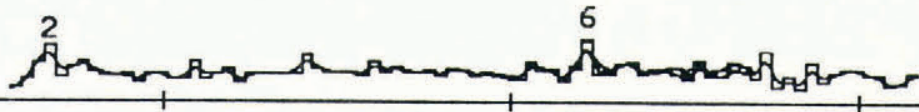

SEISMICITY LOG(counts/daY) 34

$6.9 \mathrm{~km}$ (on Rock)

SEISMICITY LOG $(c / d)$
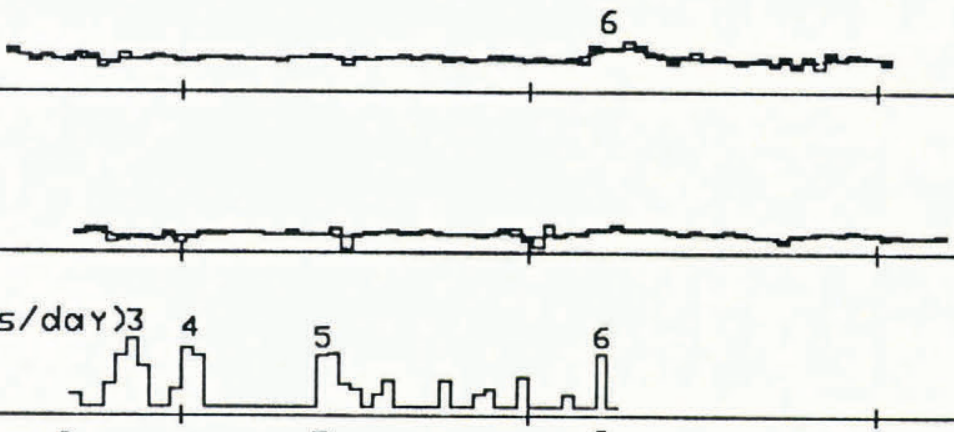

6. $9 \mathrm{~km}$ (on Glacier)

SEIS. LOG $(c / d) / 2$

- $9.8 \mathrm{~km}$ (on Glacier)

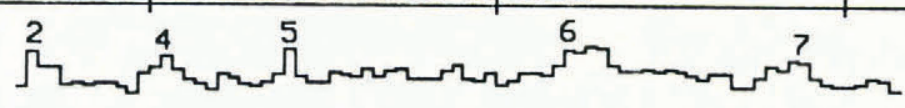

EISMICITY LOG(counts/day)
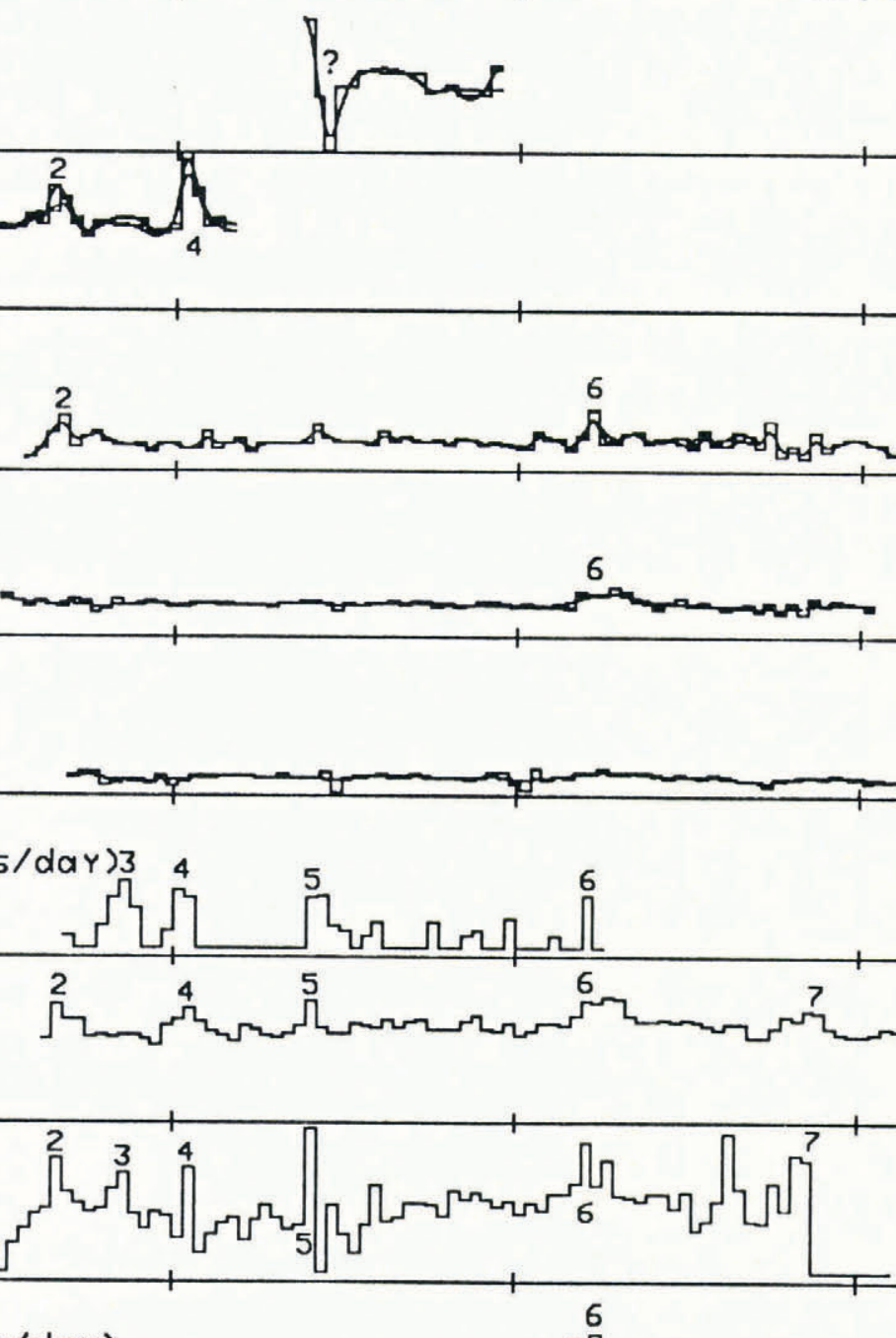
from $\mathrm{Km} 6.7$ show that the first motion event marks the acceleration of the glacier from a relatively low constant velocity over the previous month (May) to a higher baseline summer velocity with much larger fluctuations. This effect also exists in the 1979 and 1980 data, but is less obvious. The average velocity in May was close to the average over the previous winter (September to June), determined by theodolite surveying (Raymond and Harrison, in preperation). High seismic activity occurred on the lower glacier at

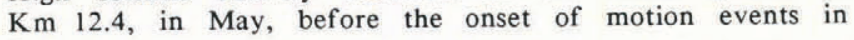
June.

\section{EVALUATION OF OBSERVATION TECHNIQUES}

The principal problems encountered in the measurement of motion with cameras were camera stability and photo timing. Other problems common to standard surveying were instability of the target and visibility.

The limitations imposed by camera instability are illustrated by comparing speed measured on a 12-hour interval, using all photographs (Figure 7), with that measured on a 24-hour interval, using one-half of the photographs from the same camera (Figure 3). The complete data set shows much sharper and higher peaks of short-

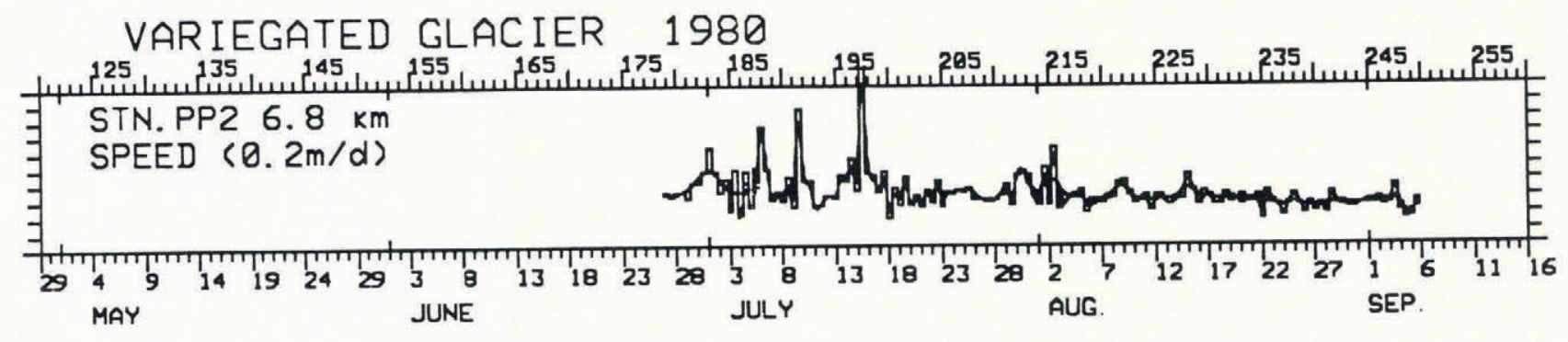

Fig.7. Horizontal speed at 12-hour intervals, using 6:00 and 18:00 data from camera at station PP2.

At $\mathrm{Km} \mathrm{6.7,} \mathrm{the} \mathrm{motion} \mathrm{events} \mathrm{were} \mathrm{not} \mathrm{quite} \mathrm{as}$ well defined as in the previous two years. Based on the direct surveying (Kamb, personal communication) and strain measurements (Raymond and Malone, in press), these motion events were strongest higher on the glacier, which is consistent with the available camera and seismometer data, but not proven by them. There were other well-defined late-season events, which followed the early season ones, including one from $7-9$ August, which broadened and became indistinct down glacier (Figure 6), but seemed to affect the lower, as well as the upper glacier. The late-season motion event of 17 August was as strong as any of the early season ones.

\section{Other years}

Although 1979 was the first year of concentrated study, motion events may have occurred during earlier years on Variegated Glacier, as indicated by speed variations of roughly $30 \%$ on a four-day time resolution near $\mathrm{Km} 9$ in 1974 (Bindschadler and others, 1977), audible cracking near Km 9 in September 1975, irregular motions, audible cracking (unpublished data), and dramatic water-level changes in boreholes (Kamb and Engelhardt, in preparation), near $\mathrm{Km} 7$ in 1978.

\section{E. Summary of short period event occurrence}

The early-season (in the sense of the early part of the melt season) motion-event activity occurred from June to mid-July, appeared to be quasi-periodic, and was restricted to the upper part of the glacier (above $\mathrm{Km} 9.4$ to 10.4). The first early-season motion event, in June, was associated with the transition from a slower winter-like speed to a faster summer baseline speed. Subsequently, early season events tended to increase in strength until the strongest in mid-July, which marked a transition to a late-season period, with events weak but affecting a substantial reach of the glacier and, finally, a strong event in late August or September, restricted to the upper glacier.

There were other types of activity that do not seem to fall into the early- or late-season motion event categories. Rather subtle examples seemed to occur on the lower glacier in 1980. Finally, although motion events were usually observed to accompany prominent seismic activity or audible cracking, this was not always the case, as noted in both 1980 and 1981 on the lower glacier. Seismicity at Km 12.4 in May 1981, before the onset of motion events, suggests some influence from melting, which started earlier there than on the upper glacier. period motion, which reflects some of the real short time-scale structure. However, the much greater background noise and a spurious diurnal component, absent in strain or surveying data, indicate errors, presumably from temperature and humidity variations acting on the film, camera, and mounting systems. Apparently spurious diurnal fluctuations were especially large in the data from stations $19 \mathrm{~s}$ and 19 in 1980. Curiously, identical cameras on the same mounts at these locations gave data with little noise in 1981. Comparison of the theodolite-surveyed and camerameasured motions in Figure 2 shows a reasonable agreement, in view of the different timing of measurements, except for an apparently erroneous double peak measured by the camera for motion event 1 . The extra peak may represent another example of instability, perhaps associated with first installation of the camera mounting pipe only two days earlier.

The principal timing uncertainty is either the possibility of multiple photographs at the same time or missed photographs. These produce either an anomalous near-zero velocity or a velocity that is about twice background, and a time shift in subsequent data. Any such difficulty is solved by using data backs, but only one was in use (at station PP1) in 1979 and 1980 and, although they were installed on all cameras in 1981, their performance was erratic. Without a data back, such problems can be partly resolved by distinguishing morning and evening photographs, correlation with known weather variation, comparison of full photographs to find duplication, or by the presence or absence of objects placed near targets at known times during the field season. We do know that data from stations 5 and 7 in 1980 (Figure 3) have unresolved timing errors and time shifts of a day are particularly possible there.

Visibility can be a greater problem for camera measurements made on a precisely regular schedule, once or twice daily, than for standard surveying where a surveyor can take advantage of brief clear periods. Fog caused the loss of many days of data from stations $19 \mathrm{~s}$ and 19 , and the tributary station BS TRIB on the upper part of the glacier (Figures 3 and 6).

The seismic data are subject to other difficulties of interpretation. The principal one is that there can be definite motion-event-like seismic-noise episodes, without definite motion anomalies, such as on 17 July 1980 (see also Figure 3 and Table I). Conversely, changes in velocity are not necessarily accompanied by anomalous seismic activity as, for example, on 23-24 July 1980. Although there is a strong correlation between motion events and anomalous 
seismic activity, it is not perfect. For this reason, seismic activity, by itself, cannot be used to prove the occurrence of motion events, although it is a good indicator.

\section{IMPLICATIONS OF THE OBSERVATIONS}

The temporal pattern of motion events can be partly explained in terms of present theoretical ideas concerning conduits, thought to comprise the principal drainage system of a glacier (Röthlisberger, 1972; Shreve, 1972; Iken and others, 1983). In this view, the dominant factor in the early melt season at a time of rising water input would be melt-water input rate that exceeds the flow capacity of the drainage system, which would have contracted through the winter. These circumstances would lead to storage of water, build-up of water pressure, and eventual injection of water over significant areas of the bed, which could initiate the first motion event. The injected water may propagate as a hydraulic wave, which would drain part of the excess stored water and lead to a speed reduction, but leave residual water at the bed and maintain a baseline velocity higher than the winter baseline. Subsequent early-season motion events would occur in similar fashion.

The time between early-season motion events may be controlled primarily by the excess of water input over drainage, which would determine the rate of water storage increase, the internal void structure of the glacier, which would determine the relationship between water storage and basal water pressure, and the threshold water pressure for injection over the bed. Once the drainage system has opened up to the point that water input is less than or equal to the drainage system capacity, the motion events would cease. This view of the early-season motion events is parallel to more quantitative interpretations based on more detailed information (Humphrey and others, in press; Kamb and Engelhardt, in preparation; Raymond and Malone, in press) and is similar to explanations of velocity variations on Unteraar Gletscher offered by Iken and others (1983).

The camera and seismic data provide the only information about late-summer motion events on Variegated Glacier. Similar concepts supply a possible explanation of their behaviour. The initial weakness of the late-season events would be due to the existence of a well-developed drainage system. As the melt-water input and discharge decrease, the internal drainage system would slowly contract. This would lead to a susceptibility to transient, short-term, water input from rainstorms or warm weather. Late in the summer, the ice surface is exposed and the remaining snow pack is ripe, so heavy rain or melt is fed rapidly into the glacier. In constrast to the early summer, the crucial factor is high variability with high input peaks. In support of this idea, one finds a correlation of every late-summer motion event with a major precipitation storm or with exceptionally warm weather (Figures 2, 3, and 6). Judging from data on a late-season event on Unteraar Glacier (Flotron, 1973), a similar explanation may hold there.

The confinement of major motion events to the upper part of the glacier is consistent with other information. On the lower glacier, basal shear stress, annual velocity, and seasonal amplitude of velocity variation were relatively constant and low from 1973 to 1981; in constrast these were larger and increased progressively on the upper glacier (Raymond and Harrison, in preparation). Based on the timing of turbidity clouds in the stream, generated by well-timed motion events, Humphrey and others (in press) have argued that the glacier drainage system was well developed beneath the lower glacier at the time of the early-season motion events on the upper glacier.

The prominence of the motion events on Variegated Glacier in the three years just before its most recent surge invites speculation that their occurrence was indicative of marginal stability and that the progressive, evolving surface geometry of the glacier drove it past these conditions to one of full surge. But since similar motion events are known on non-surge-type glaciers, it is clear such motionevent activity cannot easily be used to predict surges.

\section{ACKNOWLEDGEMENTS}

This research was supported by the U.S. National Science Foundation under grants EAR 7919529, EAR 7919530, EAR 7919424, EAR 7622500 AO1, DPP 7903942, and DPP 8200725 . The data were reduced by Diana Solie and Clifton Moore at University of Alaska, and Douglas Green and Elizabeth Senear at University of Washington. Many different people helped to deploy and maintain the cameras in the field. Logistical support was by Gulf Air Taxi and Livingston Copters, Yakutat, Alaska. Permission to work on the glacier was granted by the National Park Service and the National Forest Service.

\section{REFERENCES}

Bindschadler R, Harrison W D, Raymond C F, Crosson R 1977 Geometry and dynamics of a surge-type glacier. Journal of Glaciology 18(79): 181-194

Flotron A 1973 Photogrammetrische Messung von Gletscherbewegungen mit automatischer Kamera. Schweizerische Zeitschrift für Vermessung, Kulturtechnik und Photogrammetrie 1/73

Humphrey N, Raymond C F, Harrison W D In press Discharges of turbid water during mini-surges of Variegated Glacier, Alaska. Journal of Glaciology

Iken A, Röthlisberger H, Flotron A, Haeberli W 1983 The uplift of Unteraargletscher at the beginning of the melt season - a consequence of water storage at the bed? Journal of Glaciology 29(101): 28-47

Kamb W B and 7 others 1985 Glacier surge mechanism: 1982-1983 surge of Variegated Glacier, Alaska. Science 227(4686): 469-479

Krimmel R M, Rasmussen L A 1986 Using sequential photography to estimate ice velocity at the terminus of Columbia Glacier, Alaska. Annals of Glaciology 8:

Post A 1969 Distribution of surging glaciers in western North America. Journal of Glaciology 8(53): 229-240

Raymond C F, Malone S In press Propagating strain anomalies on Variegated Glacier, Alaska. Journal of Glaciology

Röthlisberger H 1972 Water pressure in intra- and subglacial channels. Journal of Glaciology 11(62): 177-203

Shreve R L 1972 Movement of water in glaciers. Journal of Glaciology 11(62): 205-214 